\title{
Buenos Aires en tiempos de Revolución. Centralización y confederación americana/
}

\author{
Buenos Aires in time the Revolution. \\ Centralization and American Confederation
}

\author{
Fabián Herrero
}

Universidad de Buenos Aires/

Conicet (Instituto Ravignani), Argentina

El federalismo es un componente esencial en la política de Buenos Aires después de 1820. Sin embargo, en la primera década domina la política centralista. Este trabajo estudia el concepto de confederación americana y matiza la idea histórica que habla del dominio exclusivo de los políticos centralistas. La hipótesis es que existen importantes grupos federales desde 1810 que cuestionan su poder.

Palabras Clave: Confederación; Americano; Poder; Revolución; Política.

The federacy result an essential component in the politics of Buenos Aires after 1820. Notwthstanding in the first decade command the politics centralized. This paper study the concept American confederacy and shade this historic idea. The hypothesis is that exist important federal groups after 1810 that questions politics centralize.

KEYwORDS: Confederacy; American; Power; Revolution; Politics. 
Es un hecho por demás conocido que en el cuadro político que emerge después de la Revolución, Buenos Aires figura como el campeón de la llamada tendencia centralista de poder. Las sucesivas Juntas de Gobierno, Triunviratos y Directorios constituyen las instituciones en donde esa dura y tenaz idea consigue encarnarse. Tampoco es terreno exclusivo de los especialistas el hecho de que los focos de resistencia expandan particularmente su luz desde los territorios del interior y del litoral, levantando la bandera de la llamada defensa de los derechos de los pueblos, o bien defendiendo el sistema confederal. En esta precisa línea, es frecuente detectar diversas acusaciones provenientes de esas regiones, las cuales están dirigidas a aquellas administraciones que concentran todo el poder. Bajo esta inspiración, suelen evocarse sus aristas más duras y autoritarias. Es de este modo que aquellos hombres son calificados de "mandones" e incluso resultan muchas veces incluidos dentro de los círculos de los llamados "gobiernos despóticos o arbitrarios".

En este cuadro político dicotómico, por consiguiente, no puede resultar extraña la presencia de hipótesis que señalan que pensar en la existencia de un temprano federalismo bonaerense es como una especie de despropósito o de búsqueda que escapa a cualquier lógica y a cualquier sentido. En primer lugar, se afirma que en los años iniciales de la aventura revolucionaria el federalismo es una voz inhallable en Buenos Aires, debido a que su emergencia sucede en otros territorios, tan precisos como distantes. Las opiniones se dividen. Algunos historiadores sostienen que su génesis se debe a un documento escrito en Paraguay. Como se sabe, durante el año 1811, la Junta de Paraguay solicita a su par de Buenos Aires la materialización de la denominada confederación de ciudades que, a sus ojos, ya de hecho existe. Otros consideran que esa petición no se concreta finalmente y que, a fin de cuentas, se trata de un gesto que produce escasas consecuencias. Según esta mirada de las cosas, es en la Banda Oriental en donde se desarrolla la primera experiencia federal a partir de la línea de acción impulsada por José Artigas. ${ }^{1}$

En ese marco, se afirma que el vocablo es ajeno a la realidad política porteña. Ninguna marca de ese signo habría quedado en esa arena política. En Buenos Aires, en los inicios del proceso revolucionario, señala Vicente

1 La tesis que defiende el origen oriental puede verse en Demicheli, 1962, p. 18. La posición paraguaya es sostenida por Ingenieros, 1918, p. 249; Álvarez, 1836, pp. 33 y 36; Puiggrós, 1974, pp. 81 y 84; Lynch, 1985, p. 77 y Chaves, 1959. Y también de este mismo último autor, 1941. 
Fidel López, no hay voces que sean "constitucionalmente dogma o germen federal". Desde este supuesto, concluye que "sería por demás de inconcebible...que dentro de esos elementos urbanos e internos hubiera surgido alguno con índole federal". 2

La centralista Buenos Aires discute hacia adentro de esa dura estrategia de poder, sin embargo, no se abre a considerar ninguna otra salida política. Sólo después de la sublevación de Fontezuelas, en abril de 1815, se distinguen voces de ese signo en esta provincia. ${ }^{3}$ Pero las mismas no tienen el eco que sus protagonistas sin duda esperan.

En este trabajo importa mostrar, por un lado, que la palabra federal sí circula en el espacio bonaerense en los inicios de la empresa revolucionaria, pero también que, por otro lado, lo que discuten allí remite a una forma particular de federalismo, la confederación, la cual es pensada en términos que exceden lo que hoy conocemos como territorio "nacional".

Ahora puedo volver sobre los objetivos que guían esta investigación. Me interesa analizar, en primer lugar, qué tiene para decir al respecto Mariano Moreno. Posteriormente, resulta pertinente conocer cómo un año después circula el vocablo en el diario oficial. Ambos abordajes, contradiciendo la imagen historiográfica arriba señalada, sirven para observar los aspectos relativos a las primeras manifestaciones federalistas en dominio porteño.

\section{Los “gobiernos federativos” en la mirada de Mariano Moreno}

Una de las primeras reflexiones importantes sobre los denominados "gobiernos federativos", se debe a la pluma del secretario de la primera Junta de Gobierno Mariano Moreno. Es probable que su rechazo a imponer un orden federal se explique, por una parte, por su reconocida fe en la centralización del poder revolucionario, pero es posible que, por otra parte, haya jugado su papel allí el clima de conflicto y tensión que se vive dentro de la Junta de Gobierno. La cuestión de cómo regir un inmenso territorio cruzado por diferentes tipos de conflicto, la lucha facciosa por el poder, las reclamaciones de los pueblos al poder central, los frentes de combate permanente contra una monarquía que no acepta tener un papel secundario

2 López, 1913, p. 245.

3 Especialmente Barba, 1982. Véanse capítulos 1 y 2. 
o nulo en el nuevo ordenamiento político americano, son algunos de los focos de conflicto que forman parte de un verdadero campo minado. En este contexto, pensar las formas que adquiere el poder o, mejor aún, modificar la estrategia estrictamente centralizada en Buenos Aires, no deja espacios a dudas, o se la acepta o se la combate. Vistas las cosas de este modo, podría decirse que el problema es doble: uno remite a la forma de gobierno, el otro, a la gobernabilidad.

Para comenzar, entonces, resulta oportuno describir esquemáticamente cuál es el marco político. Es conocido que la primera administración revolucionaria configura una estrategia de poder diferente. La idea de instaurar un poder fuertemente centralizado en la ciudad capital en donde se origina la revolución, y cuyo propósito sobresaliente es una conducción política que promueva y difunda los ideales y principios revolucionarios al resto de las provincias que comprenden el Río de la Plata. Esa primera fórmula política que se impone desde Mayo de 1810 rápidamente tiene dos alas o tendencias: una más radical, cuya cabeza visible es Moreno, y otra más moderada, encabezada por el coronel Cornelio Saavedra. ${ }^{4}$

Dos acontecimientos sucesivos, ocurridos en el mes de diciembre, señalan el creciente clima de tensión. El malestar dentro de la Junta se agudiza a partir del decreto, de directa redacción de Moreno, del 6 de diciembre de 1810, suprimiendo honores a Saavedra en su calidad de presidente de la Junta y comandante en jefe. El 18 de diciembre, con el importante aval de este último, la mayoría de la Junta Provisional decide que los diputados del interior formen parte de ella. Tal medida debilita ciertamente la idea de una férrea conducción política revolucionaria. Moreno, lógicamente, se opuso. Su argumento es que los diputados deben reunirse en un Congreso General y por ello no resulta conveniente que integren el poder Ejecutivo revolucionario.

Su centralismo obedece, según ha sostenido un especialista de la política del periodo, a un propósito preciso: armar y sostener una dirección revolucionaria unitaria y centralizada. Tal perspectiva, por ejemplo, se concreta en los hechos a partir de la subordinación porteña de todo tipo de autonomía. ${ }^{5}$ En este mismo sentido, otro historiador ha puesto de relieve que, bajo la impronta de Rousseau, no habría que pasar por alto que Moreno defiende la idea de una soberanía "indivisible e inalienable". ${ }^{6}$

4 Sobre las características particulares de estas tendencias ver Halperin, 1972.

5 Reyes Abadíe, 1994, p. 15.

6 Chiaramonte, 1997, p. 129. 
Exactamente, en este contexto de conflicto y de debilidad escribe el líder revolucionario sobre el federalismo. Es difícil saber de qué material de lectura dispuso a la hora de escribir. Sí se conoce que entre sus pertenencias se encuentra una Constitución de Estados Unidos, la segunda, la sancionada en 1787. Sin embargo, no está claro de quienes son las anotaciones que figuran en esos papeles. ${ }^{7}$ Unos se inclinan a pensar que son de él, otro, quizás con mas datos, propone que no es la escritura de Moreno sino la de un comerciante inglés, Alexander Mackinson. ${ }^{8}$ Lo que sí parece fuera de dudas es que tiene en mente la experiencia de Estados Unidos porque es el modelo con el que confronta sus reflexiones en torno al federalismo.

En la opinión de Moreno, la cuestión que se plantea en términos políticos bien puede formularse a partir de un interrogante: ¿podrá una parte de América por medio de sus Representantes establecer una constitución o, acaso, deberá esperar la reunión de un congreso de todo el continente? Esta alternativa parece estar destinada a fracturar la felicidad política en la que viven los flamantes revolucionarios. "Oigo hablar generalmente de un gobierno federativo — declara con cierto tono pesimista - como el más conveniente a las circunstancias y estado de nuestras provincias". ${ }^{10} \mathrm{En}$ su opinión, el error que esta propuesta contiene se vincula con la falta de conocimiento de los hombres que pretenden imponerla. Por este motivo, la iniciativa genera incertidumbre y, sobre todo, temor. "Temo, continúa nuestro escritor, que se ignore el verdadero carácter de este gobierno, y que se pida sin discernimiento una cosa que se reputará inverificable después de conocida". ${ }^{11}$

¿Cuál es ese sistema federal que los habitantes del Río de la Plata parecen desconocer y cuya instalación deben temer? Se refiere a la experiencia federalista iniciada en Norte América. De esa realidad política, señala una vertiente particular: la denominada "confederación patriarcal". Es decir, no hace referencia a la segunda Constitución de Estados Unidos (Estado Federal), vigente en esos instantes, y que como se dijo ya figura

7 Souto, 2008.

8 Ibidem.

9 Este tema, se ha señalado, lleva implícito otro más importante que se relaciona con la extensión geográfica del nuevo Estado en la América española. De sus argumentaciones surge con claridad la voluntad de constituir una nueva nación. Pero, consideraciones de orden político que guían igualmente estas reflexiones, conducen a Moreno a juzgar inviable la unidad americana, aconsejando a sus compatriotas la solución más limitada de la reunión de un congreso sólo de las provincias del Virreinato. Ibidem.

10 La Gazeta, 6 de diciembre de 1810.

11 Ibidem. 
entre sus materiales de trabajo. ${ }^{12}$ Para conocer cómo la define es necesario volver a escucharlo:

"Esta consiste, esencialmente, en la reunión de muchos pueblos o provincias independientes unas de otras, pero sujetas al mismo tiempo a una dieta o consejo general de todas ellas, que decide soberanamente sobre las materias de estado que tocan al cuerpo de nación". ${ }^{13}$

Como se ve, cuando habla de federalismo está hablando en rigor de una confederación. La importancia y la vigencia de este experimento político no se pone en duda. "Este sistema, dice el líder revolucionario, es el mejor, quizá, que se ha discurrido entre los hombres." Sin embargo, su aplicación en nuestras tierras le resulta tan complicada que se atreve a decir que “difícilmente podrá aplicarse a toda la América". Porque a sus ojos es imposible cumplir con sus principios básicos. "Dónde se formará, se apresura a apuntar nuevamente, esa gran dieta ni cómo se recibirán instrucciones de pueblos tan distantes para las urgencias imprevistas del estado". ${ }^{14} \mathrm{~A}$ esta lista de dificultades, le agrega otros dos datos de la realidad histórica, que, ciertamente, considera muy problemáticos: la inmensidad del territorio y la urgencia cotidiana de la guerra revolucionaria que obliga a los gobernantes a tomar rápidas decisiones. ${ }^{15}$

Sin embargo, más allá de su rechazo sobre la fórmula confederal, no se permite pasar en silencio sobre qué tipo de organización política sería deseable. Así, sostiene que para un tiempo más tranquilo (y sobre todo futuro) preferiría una alianza: cada provincia de América, dice Moreno, debería establecer su constitución en sus propios límites de acuerdo a sus costumbres y necesidades, esto es, "a lo que considere más conveniente para su felicidad". ${ }^{16} \mathrm{Al}$ mismo tiempo, señala que cada territorio del continente debe asumir una alta y solidaria misión, la "justa máxima de auxiliarse y socorrerse mutuamente".${ }^{17}$ En ese marco, sostiene que debe abandonar-

12 "Los pueblos modernos son los únicos que nos han dado una exacta idea del gobierno federativo, y aún entre los salvajes de América (se refiere a los de Estados Unidos) se ha encontrado practicado en términos que nunca conocieron los griegos. Oigamos a Mr. Jefferson que en las observaciones sobre la Virginia, nos describe todas las partes de semejante asociación...He aquí un estado admirable, que recurre al gobierno patriarcal la forma rigurosa de una federación." (cursiva mía) $L a$ Gazeta, 6 de diciembre de 1810.
13 Ibidem.
14 Ibidem.
15 Ibidem.
16 Ibidem.
17 Ibidem. 
se cualquier idea federalista, la cual resulta en estos momentos "inverificable". ${ }^{18}$ De este modo, sus reflexiones en torno al federalismo, no pueden, de ningún modo, ser asimiladas a las de un entusiasta divulgador de este tipo de ideas como lo sugiriera uno de los primeros historiadores nacionales. Me refiero a Bartolomé Mitre, quien anota que la federación es "explicada y propagada dogmáticamente su doctrina por Moreno". ${ }^{19}$

¿Cuál es la intención política de estas reflexiones del jefe revolucionario? Es difícil saberlo con certeza, ya que nuestro escritor sólo señala su disgusto por el rumor de un posible gobierno federativo y parece únicamente estar dispuesto a decir por qué su realización material constituiría un serio error. No da nombres ni los sugiere. Es muy probable (si se me permite hacer una conjetura) que su negativa con respecto a la idea de implantar una confederación se deba, por lo menos en parte, a la incorporación de los diputados del interior a la Junta de gobierno porteña. Aceptar las bondades de ese sistema significa aceptar los derechos políticos autónomos y soberanos de las ciudades y provincias que esa Junta controla y dirige políticamente en las citadas fechas. No es gratuito (y mucho menos inocente) que el federalismo sea una de las armas de combate elegidas por las provincias durante toda la década revolucionaria. Especialmente con el fin de hacer dos tipos de impugnaciones: para cuestionar el poder central de los gobiernos porteños y para, claramente, justificar y sostener su participación dentro del marco de la política nacional. El federalismo, de este modo, oficiaría como una suerte de caja de herramientas utilizada por aquellos que cuestionan la posición política hegemónica de Buenos Aires. Políticamente, está pensando en términos americanos y no en términos de lo que hoy llamamos territorio argentino. La revolución ha comenzado hace poco y aun no están fijados sus límites.

\section{La idea de confederacionismo fidelista de hecho en los papeles públicos porteños}

Durante el año 1811, y en algunos papeles públicos relacionados con la Junta de Gobierno de Buenos Aires, es posible detectar el vocablo federal como una suerte de confederacionismo fidelista de hecho. En términos generales, significa la unión de todas las partes que integran el reino espa-

19 Mitre, 1968, p. 21. 
ñol y el reconocimiento del soberano. También es posible que se aluda con ello a aquellas naciones que sostienen una alianza con España.

Un buen ejemplo puede observarse en una página escrita por el redactor de La Gazeta, en donde se presentan las reflexiones del editor del Correo Brasiliense. Este papel se ocupa centralmente de la realidad europea, más precisamente, de España, Inglaterra y Francia. Es evidente aquí que el término confederación es sinónimo de pacto, de alianza con aquellos países que están aliados a la nación española. Bien vale recordar que en esos instantes España e Inglaterra se han unido contra Francia. Otro elemento a tener presente es la posibilidad de una mediación británica en el conflicto entre España y sus antiguas colonias. ${ }^{20}$ En esta línea, el editor del diario oficial de Buenos Aires reprodujo un articulo escrito por el clérigo sevillano José María Blanco White, ${ }^{21}$ aparecido en El Español (publicación periódica editada en Londres), en el cual, utilizando documentación extraída al parecer de fuentes francesas, da cuenta de una tentativa por parte del gobierno inglés para liberar a Fernando VII.

En este marco de verdadera simpatía y solidaridad entre algunas naciones europeas, debe entenderse por qué pueden hallarse afirmaciones como esta:

“...odio eterno al usurpador, y fidelidad a Fernando, estos son unos principios sagrados que jamás violaremos, y que reconocemos siempre por la base de nuestra alianza y confederación con la generosa nación inglesa". ${ }^{22}$

20 Pasino, 2004, pp. 68 y 69.

21 "Blanco White ocupó un lugar destacado y polémico en el proceso revolucionario español iniciado en 1808. Desde las páginas del Semanario Patriótico —órgano político del grupo liberal de Manuel Quintana- alentó la convocatoria a Cortes generales y extraordinarias desde una perspectiva no estamental, proclamó la soberanía de la nación y bregó por la libertad de expresión como único medio para aunar los esfuerzos de la guerra de independencia — con su carga popular y religiosa — con la sanción de un texto Constitucional que limitara los poderes del monarca y diera paso a la modernización de España. La oposición que encontró por parte de la Junta Central —encargada de la convocatoria de Cortes - lo condujo a su exilio en Londres. Sus relaciones con Lord Holland — a quien había conocido en Sevilla en 1809- le posibilitaron el acceso al círculo Whig de la Holland House. Al mismo tiempo, la capital inglesa constituía en esos años el principal centro político europeo de los revolucionarios hispanoamericanos. Debido a ello, tuvo contacto con Miranda, Bolívar, Andrés Bello, Fray Servando Teresa de Mier y Manuel Moreno, entre otros. Sus escritos en esta etapa son los más destacados de su obra política. En las páginas de El Español expuso sus duras críticas hacia el accionar de los liberales gaditanos en las Cortes, la conducción de la guerra y el propio texto constitucional. Pero el aspecto más polémico fue la referencia a los territorios hispanoamericanos desde la presentación del periódico. Esto lo convierte en el primer liberal español que analizó los efectos de la revolución española sobre sus colonias, cuestionando la desigual representación otorgada a los americanos en las Cortes y reclamando la sanción del libre comercio como principal antídoto para evitar la separación.". Ibidem, pp. 55 y 56.

22 "Continúan las reflexiones del editor del Correo Brasiliense". La Gazeta, 29 de agosto de 1811. La cursiva es mía. 
Otro ejemplo alude al conocido tratado firmado entre los gobiernos de Buenos Aires y Paraguay. Aquí el vocablo confederacionismo es usado como una alianza preexistente de nación, la cual no remite ni a una supuesta estructura política nacional argentina ni americana, sino a la nación española. Dentro de esta perspectiva, en los meses de septiembre y noviembre de 1811, aparecen en La Gazeta artículos referidos a ese tratado. ${ }^{23}$ En este documento, la Junta de Paraguay explica su actitud separatista sosteniendo que, reasumiendo los pueblos sus derechos primitivos legítimos, se hallan todos ellos en iguales condiciones. Desde este supuesto, se afirma que

“...los autos mismos manifestarán a VE (se refiere a la Junta Gubernativa de Buenos Aires) que su voluntad decidida es unirse con esa ciudad, y demás confederadas no sólo para conservar una recíproca amistad, buena armonía, comercio y correspondencia, sino también para formar una sociedad fundada en principios de justicia, de equidad y de igualdad. A este fin ya ha nombrado su diputado, para que asista al Congreso general de las provincias...". ${ }^{24}$

Varias son las interpretaciones que este texto merece. Una de ellas remite a su origen ideológico. "Ésta fue la primera vez, escribió Bartolomé Mitre en su clásica Historia de Belgrano, que resonó en la historia Argentina la palabra federación, tan famosa después en sus guerras civiles, en sus congresos constituyentes y en sus destinos futuros". ${ }^{25}$

Otra alude a su trasfondo político e ideológico. La forma de organización de poder no puede ajustarse a cualquier noción federalista, sino que los hombres que la enuncian y defienden la usan en un sentido concreto: como una confederación. ${ }^{26}$ Se ha hecho notar, asimismo, que el fundamento de los textos federalistas paraguayos de este periodo proviene de la veta del derecho natural y de gentes. El objeto del Congreso General de las Provincias propuesto por Buenos Aires, a juicio de quienes el 9 de junio de 1811 separaron del mando al gobernador Bernardo de Velazco, debía ser el de "formar una asociación justa, racional, fundada en la equi-

23 A este tema Carlos Segretti le ha dedicado un capítulo en Segretti, 1995, pp. 7-17.

24 "Oficio de la Junta Provisional del Paraguay, en que da parte a la de la capital de su instalación, y unión con los vínculos más estrechos e indisolubles, que exige el interés general en defensa de la causa común de la libertad civil de la América, que tan dignamente se sostiene", La Gazeta, 5 de setiembre de 1811. El documento está fechado en Asunción el 20 de julio de 1811. Ibidem. La cursiva es mía.

25 Mitre, 1968, p. 21.

26 Véase Segretti, 1995. 
dad y en los mejores principios de derecho natural, que son comunes a todos". ${ }^{27}$

En tercer término, se ha señalado con entera claridad que el proceso que llevó a la materialización de dicho tratado es más lento de lo que se supone y que ese camino está lleno de promesas políticas. Los agentes porteños en Paraguay tienen un lenguaje proclive a la autonomía paraguaya durante todo ese año con el fin de lograr que aquellos se sumen a la revolución de Buenos Aires. En las entrevistas que Belgrano mantiene con los jefes militares paraguayos, durante 1811, trata de convencerlos de que se unan a la revolución “argumentando que Buenos Aires respetaría no sólo la autonomía de la provincia sino que la liberaría de las cargas impositivas que pesaban sobre sus productos de exportación, el tabaco y la yerba mate". ${ }^{28}$

Sin embargo, lo que no se ha advertido aún es que esa confederación está atada a la figura del rey, esto es, no se trata de una confederación que una en un mismo espacio de poder a distintas entidades políticas sin ningún lazo exterior, sino que es una confederación de corte fidelista:

“... la provincia no podía dar una prueba más positiva de sus sinceros deseos de accesión a la confederación general, y de defender la causa común del señor D. Fernando VII y de la felicidad de todas las provincias, que tan heroicamente promueve V.E.". ${ }^{29}$

No debe entenderse como una novedad, ya que la apelación al rey está en el centro del discurso paraguayo y porteño. A comienzos de 1811, y en medio de sangrientos combates, Belgrano explica por medio de proclamas que su ejército, compuesto por amigos y paisanos con "una misma religión, leyes, idioma y rey”, había ido a auxiliar al Paraguay, a suprimir el inicuo

27 En igual sentido, sostiene el mismo autor que "entre esos principios de derecho natural figuraba en primer término el del consentimiento, requisito ineludible para que cada parte de una nueva entidad política fuera incluida en ella, así como la formalización del pacto de sociedad necesario para darle forma. Tales rasgos iusnaturalistas se observan también en la resolución del Congreso General de la Provincia reunido en Asunción el 17 de junio de 1811, que manifiesta la disposición del Paraguay de establecer no sólo relaciones de amistad con Buenos Aires "y demás provincias confederadas, sino que también se una con ellas para el efecto de formar una sociedad fundada en principios de justicia, de equidad y de igualdad”. En Chiaramonte, 2004, p. 78.

28 Areces, 2005, p. 65.

29 "Oficio de la Junta Provisional del Paraguay, en que da parte a la de la capital de su instalación, y unión con los vínculos más estrechos e indisolubles, que exige el interés general en defensa de la causa común de la libertad civil de la América, que tan dignamente se sostiene", La Gazeta, 5 de septiembre de 1811. El documento está fechado en Asunción el 20 de julio de 1811. Ibidem. La cursiva es mía. 
servicio de milicias e iniciar un comercio libre de todos los productos paraguayos, aun del tabaco. ${ }^{30}$ En febrero, la Junta porteña avala esas proclamas.

Tal situación se entiende por las circunstancias críticas que vive Buenos Aires. Especialmente el año 1811 se muestra como un periodo poco provechoso en la resolución de conflictos; cuando se negocia este tratado, la ciudad capital vive las consecuencias aún de los sucesos de abril, en los que los moderados de Saavedra, respaldados por un movimiento urbano y suburbano encabezados por algunos alcaldes de Barrio, logran depurar momentáneamente al sector morenista de la vida pública de la ciudad. En los primeros días de agosto se conoce al mismo tiempo en la capital la derrota de Huaqui, que, básicamente, brinda una victoria contundente a los realistas en el Alto Perú. También se produce, casi al mismo tiempo, la invasión portuguesa de Diego de Souza a la Banda Oriental en apoyo de Elío. En septiembre, finalmente, emerge con entera claridad una crisis en el gobierno de Buenos Aires que, entre otras cuestiones, motiva que sus miembros más importantes se alejen de la ciudad. Un último aspecto, como ha llamado la atención Halperin, alude a la mirada militar que desde Buenos Aires se tiene con relación a la guerra contra los ejércitos realistas. En este sentido, se ha insistido que una de las preocupaciones claves desde el comienzo de la guerra revolucionaria es la situación de la Banda Oriental ya que desde allí, se sospecha (y con razón), pueden venir los golpes decisivos de los españoles. Ante el avance de los portugueses durante ese año, Montevideo y Buenos Aires firman un armisticio, una alianza defensiva contra esta invasión. ${ }^{31}$

En este contexto, Buenos Aires presenta una situación de debilidad política. Por ello cede su posición coyunturalmente (sólo coyunturalmente) tanto en Paraguay como en la Banda Oriental, en cuanto estos tratados no son ratificados con posterioridad por el gobierno porteño, mostrando claramente que no está dispuesto a ceder sus derechos. ${ }^{32}$

30 Areces, 2005 p. 65.

31 Reyes Abadíe, 1994, p. 23. El mismo autor explica las circunstancias de la petición de ayuda del virrey Elío a los portugueses y el posterior armisticio entre el gobierno de Buenos Aires y los portugueses. Ibidem, pp. 73 y 74. De esa manera, concreta un pacto de paz con Montevideo en octubre de 1811: la entera campaña oriental, y aún la mitad oriental de Entre Ríos, son devueltas a la obediencia montevideana, se espera de este modo alejar a los ocupantes portugueses, cuya intervención había sido presentada como una defensa de la amenazada autoridad del rey de España. El armisticio de 1811 entregaba la costa entrerriana a los realistas. Es decir, en mayo el gobierno de Buenos Aires defiende a Montevideo como parte de la nación española. Halperin Donghi, 1972, pp. 283 y 297.

32 Ibidem. 
Es muy probable que esta idea de confederación se vincule de algún modo con la de conformar un nuevo modelo imperial. Ese modelo es impulsado por Blanco White y es aceptado, aunque con algunas reservas, por el sector moderado de la revolución..$^{33}$ Las primeras reproducciones de El Español aparecen en La Gazeta cuando el Deán Funes se hace cargo de su edición. El articulo trata sobre la situación americana en el contexto de la formación de las Juntas de gobierno en Caracas y Buenos Aires. En esas páginas no sólo se celebraba la moderación de la revolución de Caracas sino que se la considera como el primer e imprescindible paso para la conformación de un nuevo tipo de moderación imperial. ¿En qué consiste? Se basa, como la ha puesto de relieve Alejandra Pasino, en la existencia de un conjunto de provincias y reinos, provistos de gobiernos autónomos para sus aspectos locales, que se asimilan a un sistema confederado bajo el reconocimiento de la figura del monarca.

La legitimidad de las Juntas formadas en Caracas y Buenos Aires $-\mathrm{y}$ las que a su entender deberían formarse en todos los antiguos territorios coloniales - se argumenta en el marco del proceso revolucionario iniciado en la Península en 1808, es decir, la formación de las Juntas locales y provinciales. A los ojos del sevillano, la característica esencial es que dichos gobiernos no deben olvidar su función de "interinos" hasta el regreso del monarca o hasta que una autentica representación de los territorios españoles y americanos siente las bases del nuevo imperio.

En suma, la idea de confederación fidelista de hecho le sirve a la Junta para ofrecer alguna respuesta tanto a su relación con la Península como a la constante reclamación de los pueblos por su preciada autonomía. Sin embargo, lo que no debemos perder de vista, más allá de estas menciones de otro cariz político, es que en el discurso de los gobiernos de Buenos Aires predomina la idea centralista de poder. El empleo del concepto de confederación fidelista de hecho ${ }^{34}$ es efímero y coyuntural, coincidiendo su uso con las frecuentes crisis políticas registradas en el marco de la revolución y la guerra. El uso del confederacionismo, de hecho, es empleado de manera coyuntural durante el año 1811. A lo largo de 1812 resulta menos

33 Pasino, 2004, pp. 65 y 66.

34 Véase, "Mendoza", La Gazeta, 25 de abril de 1811. Está fechado en el lugar el 27 de marzo de 1811. Otros ejemplos pueden consultarse en "Respuesta de D. José Obregón, parlamentario de Montevideo dada por la Excma Junta, 27 de mayo de 1811”, La Gazeta, 30 de mayo de 1811. En este sentido, ver también: "Manifiesto Apologético de la Junta Gubernativa de Buenos Aires a los Pueblos de la Confederación", Buenos Aires, 5 de septiembre de 1811. Archivo del Instituto de Historia Argentina y Americana Dr. Emilio Ravignani (AIHAAER), Buenos Aires, 1811. 
visible. Y durante el año 1813 se la cuestiona directamente..$^{35}$ Es del todo probable suponer que su disminución coincida con la emergencia del caudillo federal José Artigas que, en estos últimos años, lentamente, se convierte en una alternativa de poder frente a los gobiernos de Buenos Aires.

\section{A modo de conclusión}

—En Buenos Aires, el vocablo federal, no aparece como un relámpago inesperado en los días posteriores a la sublevación de Fontezuelas, en donde comienza a circular como una propuesta de renovación y cambio en algunos grupos políticos locales. Como se ha destacado en estas páginas, esa realidad (supuestamente ajena) ya es palpable antes. Un murmullo federalista, a veces audible, otras casi imperceptible, comienza a circular durante 1810 y 1811 . De este modo, la afirmación de que no hay una voz federal en territorio bonaerense en los inicios de la Revolución no se asimila al paisaje político de esos días: la improbable confederación americana descrita por Moreno en las columnas del diario oficial, la idea de una confederación fidelista de hecho escrita en algunos artículos de La Gazeta y en papeles de gobierno, y las ideas federales de los partidarios de Artigas en la ciudad puerto, ${ }^{36}$ hacen enteramente visible que el vocablo no es ajeno a la realidad política local. De este modo, en la Buenos Aires centralista del decenio revolucionario, es posible describir un escenario más abierto a las creencias de este signo.

-El concepto político confederacionismo americano merece varios comentarios. Para su mejor comprensión es necesario desmontarlo. En esta línea, resulta de suma utilidad analizar y explicar cada uno de esos vocablos. La confederación, entendida como una unión laxa de provincias o de ciudades que mantiene su propia soberanía bajo el amparo de un gobierno

35 Hemos detectado un sentido de confederacionismo para expresar con él la posibilidad de una alianza preexistente enemiga. En la Asamblea Constituyente de 1813, reunida en Buenos Aires, se menciona la presencia de una alianza enemiga que acaba de romperse, se refiere a las intendencias de Charcas, Potosí, Cochabamba y La Paz. En este caso, la confederación remite a la nación española, pero se usa como una noción negativa lógicamente porque se esta peleando contra aquellos. En esa línea, se dice en la sesión del 29 de abril de 1813: "Destruidas en la campaña de Salta las últimas fuerzas de la confederación despótica, es llegado el feliz momento en que las provincias occidentales de la unión nombren sin demora sus legítimos representantes para esta Asamblea...” Sesión del lunes 29 de abril de 1813, en Asambleas Constituyentes, Buenos Aires, 34.

36 Véase Fabián Herrero, 2000 y 2005. 
central que las preside pero con menos atribuciones de poder que ellas, constituye una de las variantes federales; las otras dos son el estado federal y la vertiente de Benjamín Constant, que, cada una a su modo, ponen el acento de la soberanía más en el poder central que en las partes del todo. Aquel concepto, durante toda la década de 1810, es dominante entre las voces de ese signo, en Representaciones de vecinos, en cartas, en la prensa, puede advertirse por ejemplo en 1815, 1816, 1817 y finalmente en $1820 .{ }^{37}$

Sin embargo, en este estudio he analizado una segunda forma confederal, cuya diferencia central con la primera no está en sus contenidos elementales y básicos sino en las dimensiones territoriales en que es pensada. Esa dimensión no es nacional sino continental. He tratado de hacer ver cómo hay actores que piensan en las posibilidades de instalar una confederación en una escala mayor, americana. Las reflexiones de Mariano Moreno sobre las posibilidades de un sistema federal de dimensión americana, la circulación del vocablo confederación como una situación de hecho y de corte fidelista, señalan con entera claridad esta última perspectiva.

Estas intervenciones, por cierto, no han operado políticamente en un modo decisivo sino que circularon de modo coyuntural, esto es, no están en la mesa de la discusión pública todo el tiempo. El confederacionismo fidelista de hecho funcionó como un componente ideológico defensivo por parte de las Juntas de gobierno de Buenos Aires, en momentos de clara debilidad política en donde se trata de ceder a las reivindicaciones de mayor participación política por parte de las provincias. Una vez pasada la tormenta política, la centralista Buenos Aires retoma su estrategia de poder conocida durante toda esa década, la subordinación de las provincias a un poder centralizado radicado en esta ultima ciudad. Las reflexiones negativas de Moreno sobre el tema también se dan en un momento de fragilidad política del gobierno porteño, donde uno de sus líderes tiene que salir a escena a explicar su inviabilidad. Esas reflexiones, por este orden de razones, sólo duran los días de esa crisis.

Recibido el 2 de septiembre de 2008 Aceptado el 23 de Septiembre de 2010

37 Analizo todos esos casos en Fabián Herrero, 2000. Sobre las posturas de los grupos contrarios al federalismo, véase del mismo autor, 2010. 


\section{BUENOS AIRES EN TIEMPOS DE REVOLUCIÓN}

\section{Bibliografía}

Juan Álvarez: Las guerras civiles argentinas y el problema de Buenos Aires en la República Argentina, Buenos Aires, La Facultad, 1836.

Nidia Areces: "Capital político y soberanía en Paraguay: de la independencia a la conspiración de 1820”, Dimensión Antropológica, año 12, vol. 35, México, septiembre-diciembre de 2005.

Archivo del Instituto de Historia Argentina y Americana Dr Emilio Ravignani (AIHAAER), Archivo de Vicente de Echeverría, (1811-1840), Legajo n. ${ }^{\circ}$ 2, Documento n. ${ }^{\circ}$ 669, fs.1209-1227.

Enrique Barba: Unitarismo, federalismo, rosismo, Buenos Aires, CEAL, 1982.

Julio César Chaves: Historia de las relaciones entre Buenos Aires y el Paraguay, 1810-1813, Buenos Aires, 1959.

- El Plan federal del Dr. Francia, Buenos Aires, 1941.

José Carlos Chiaramonte: Ciudades, provincias, estados: orígenes de la Nación Argentina (1800-1846), Buenos Aires, Ariel, 1997.

- Nación y Estado en Iberoamérica. El lenguaje político en tiempos de las independencias, Buenos Aires, Editorial Sudamericana, 2004.

Alberto Demicheli: Origen federal argentino, Buenos Aires, Depalma, 1962.

Tulio Halperin Donghi: Revolución y Guerra. Formación de una elite dirigente en la Argentina criolla, Buenos Aires, Siglo XXI, 1972.

Fabián Herrero: Federalistas de Buenos Aires. Sobre los orígenes de la política revolucionaria, Tesis de Doctorado, Universidad de Buenos Aires, 2000.

- Monteagudo. Revolución, independencia, confederacionismo, Buenos Aires, Ediciones Cooperativas, 2007.

- "Escenarios antifederalistas: rechazar la fragmentación del poder y defender el protagonismo de Buenos Aires", Secuencia. Revista de historia y ciencias sociales, México, n. ${ }^{\circ}$ 76, enero-abril de 2010.

José Ingenieros: La evolución de las ideas Argentinas, Libro 1, Buenos Aires, La Revolución, 1918.

Vicente Fidel López: Historia de la República Argentina. Su origen, su revolución y su desarrollo político, Buenos Aires, 1913, tomo IV.

John Lynch: Las revoluciones hispanoamericanas, 1808-1826, Buenos Aires, Ariel, 1985.

Bartolomé Mitre: Historia de Belgrano y de la Independencia Argentina, Buenos Aires. Editorial Universitaria de Buenos Aires, 1968, tomo II.

Alejandra Pasino: "El Español de José María Blanco White en la prensa porteña durante los primeros años revolucionarios", en Fabián Herrero (comp.): Revolución. Política e ideas en el Río de la Plata. Buenos Aires, Ediciones Cooperativas, 2004.

Rodolfo Puiggrós: Historia económica del Río de la Plata, Buenos Aires, A. Peña Lillo Editor SRL, 1974. 


\section{FABIÁN HERRERO}

Emilio Ravignani (comp.): Asambleas Constituyentes Argentinas. Seguidas de los textos constitucionales, legislativos y pactos interprovinciales, que organizaron políticamente la Nación, 1813-1833, Buenos Aires, Peuser, 1937-1939, 6 vols.

Washington Reyes Abadíe: Artigas y el federalismo en el Río de la Plata, 18101820, Montevideo, Ediciones de la Banda Oriental, 1994.

Nora Souto: "Unidad/Federación”, en Noemí Goldman (ed.): Lenguaje y revolución. Conceptos políticos clave en el Río de la Plata, 1780-1850, Buenos Aires, Prometeo, 2008.

Carlos Segretti: Federalismo rioplatense y federalismo argentino, Córdoba, Centro de Estudios Históricos, 1995. 